\title{
Author Correction: Identification of a Novel Feruloyl Esterase by Functional Screening of a Soil Metagenomic Library
}

\author{
Xuanxuan $\mathrm{Li}^{1} \cdot \mathrm{Jia} \mathrm{Guo}^{1} \cdot$ Yimin $\mathrm{Hu}^{1} \cdot$ Yumeng Yang ${ }^{1} \cdot$ Junwei Jiang ${ }^{1} \cdot$ Fang Nan $^{1}$ • \\ Shenglu $\mathrm{Wu}^{1} \cdot$ Zhihong Xin $^{1}$ \\ Published online: 26 February 2019 \\ (C) Springer Science+Business Media, LLC, part of Springer Nature 2019
}

\section{Author Correction: Applied Biochemistry and Biotechnology (2019) 187:424-437 https://doi.org/10.1007/s12010-018-2832-1}

The original version of this article unfortunately contained a mistake in the image and caption of Fig. 6 . The corrected version of the image and caption is shown here.

The online version of the original article can be found at https://doi.org/10.1007/s12010-018-2832-1

Zhihong Xin

xzhfood@njau.edu.cn

Xuanxuan Li

2016808110@njau.edu.cn

Jia Guo

2015208019@njau.edu.cn

Yimin $\mathrm{Hu}$

2015108060@njau.edu.cn

Yumeng Yang

2015108059@njau.edu.cn

Junwei Jiang

2016108058@njau.edu.cn

Fang Nan

2016108057@njau.edu.cn

Shenglu Wu

2016108059@njau.edu.cn

1 Key Laboratory of Food Processing and Quality Control, College of Food Science and Technology, Nanjing Agricultural University, Nanjing 210095, People's Republic of China 


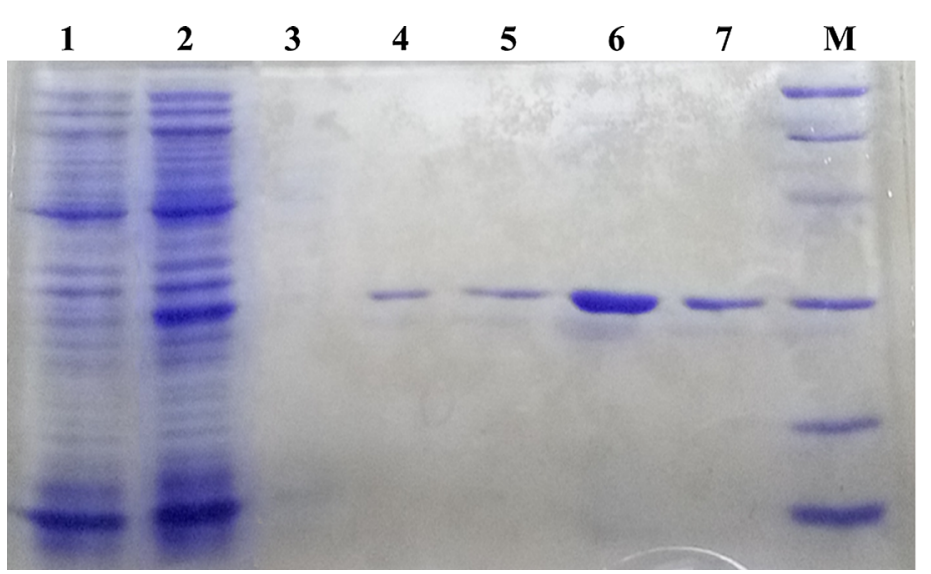

kDa

97.2

66.4

44.3

29

20.1

14.3

Fig. 6 SDS-PAGE analysis of FAE-Xuan. Lane 1: negative control (E. coli harboring the empty pET28a). Lane 2: crude protein extracts of recombinant cells. Lane 3: $20 \mathrm{mM}$ imidazole elution. Lane 4: $100 \mathrm{mM}$ imidazole elution. Lane 5: $200 \mathrm{mM}$ imidazole elution. Lane 6: $300 \mathrm{mM}$ imidazole elution. Lane 7: $400 \mathrm{mM}$ imidazole elution. M: Protein marker Lane M: standard protein marker

The author apologizes for this oversight and for any confusion it may have caused.

Publisher's Note Springer Nature remains neutral with regard to jurisdictional claims in published maps and institutional affiliations. 